\title{
GILLES BANDERIER, Un livre ayant appartenu à Jean- Baptiste Chassignet
}

\section{Filippo Fonio}

\section{(2) OpenEdition \\ Journals}

\section{Edizione digitale}

URL: http://journals.openedition.org/studifrancesi/33063

DOI: 10.4000/studifrancesi.33063

ISSN: 2427-5856

\section{Editore}

Rosenberg \& Sellier

\section{Edizione cartacea}

Data di pubblicazione: 1 décembre 2005

Paginazione: 630

ISSN: 0039-2944

\section{Notizia bibliografica digitale}

Filippo Fonio, "GiLles BANDERIER, Un livre ayant appartenu à Jean-Baptiste Chassignet», Studi Francesi [Online], 147 (XLX | III) | 2005, online dal 01 novembre 2015, consultato il 19 avril 2021. URL: http:// journals.openedition.org/studifrancesi/33063 ; DOI: https://doi.org/10.4000/studifrancesi.33063

Questo documento è stato generato automaticamente il 19 avril 2021.

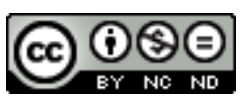

Studi Francesi è distribuita con Licenza Creative Commons Attribuzione - Non commerciale - Non opere derivate 4.0 Internazionale. 


\section{GILLES BANDERIER, Un livre ayant appartenu à Jean-Baptiste Chassignet}

Filippo Fonio

\section{NOTIZIA}

GILLES BANDERIER, Un livre ayant appartenu à Jean-Baptiste Chassignet, «Bibliothèque d'Humanisme et Renaissance», LXVI, 2 (2004), pp. 403-404.

1 Si comunica il rinvenimento, presso la Bibliothèque Municipale di Troyes, di una copia degli Epithetes di Maurice de La Porte nell'edizione 1592, appartenuta a Jean-Baptiste Chassignet. Già Yvonne Bellenger riscontrava delle analogie fra la raccolta di Chassignet, Mespriz de la vie et consolation contre la mort, e gli Epithetes, nel contributo presentato al colloque di Besançon dedicato al poeta (Jean-Baptiste Chassignet, OLIVIER MILLET ed., Paris, Champion, 2003). 